\title{
Multiple Coronary Chamber Microfistulas or Persistent Thebesian Vessels?
}

\author{
Daniel Cernica', Lehel Bordi', Elena Beganu', loana Rodean', Imre Benedek1,2 \\ 1 Center of Advanced Research in Multimodality Cardiac Imaging, Cardio Med Medical Center, Tîrgu Mureș, Romania \\ 2 University of Medicine and Pharmacy, Tîrgu Mureș, Romania
}

\section{CORRESPONDENCE \\ Lehel Bordi \\ Str. 22 Decembrie 1989 nr. 76 \\ 540124 Tîrgu Mureș, Romania \\ Tel: +40 265217333 \\ E-mail: bordi_lehel:gmail.com}

\section{ARTICLE HISTORY}

Received: June 13, 2017

Accepted: July 27, 2017
Daniel Cernica • Str. 22 Decembrie 1989 nr. 76 , 540124 Tîrgu Mureș, Romania. Tel: +40 265217333. E-mail: daniel.cernica@gmail.com

Elena Beganu • Str. 22 Decembrie 1989 nr. 76 540124 Tîrgu Mureș, Romania. Tel: +40 265217333. E-mail: beganu.elena@yahoo.com

Ioana Rodean • Str. 22 Decembrie 1989 nr. 76 540124 Tîrgu Mureș, Romania. Tel: +40 265217333. E-mail: ioana_patricia@yahoo.com

Imre Benedek • Str. Gheorghe Marinescu nr. 38 540139 Tîrgu Mures, Romania. Tel: +40 265215551.

E-mail: imrebenedek@yahoo.com

\begin{abstract}
Coronary fistulas are rare, not gender-specific congenital conditions, consisting of communications between the coronary arteries and either another coronary vessel or a cardiac chamber In contrast to large fistulas, small fistulas, named "minimae cordis veneae" or the Thebesius venous system, are draining into heart chambers and form a vascular network in the cardiac lumen. In this article, we present the case of a 72-year-old female with a significant history of cardiovascular disease, admitted to our clinic because of rest dyspnea, fatigue, and minimal chest pain. The 12-lead electrocardiogram showed a trifascicular block (a second-degree atrioventricular block Mobitz II, associated with a right bundle branch block and left anterior fascicle block) and negative T waves in DII, DIII, aVF, V4-V6 leads. An invasive coronary angiography was performed, which revealed no significant atherosclerotic lesions. However, a persistent capillary blush was present at the apex site of the left ventricular chamber, draining from the distal segments of both the anterior descending coronary artery and the posterior interventricular coronary artery. The intramural vascular network generating a left ventricle angiogram image of this kind was suggestive for persistent Thebesian vessels connecting the two coronaries with the left ventricular chamber.
\end{abstract}

Keywords: coronary-cameral fistula, Thebesian vessels, congenital fistula

\section{INTRODUCTION}

Coronary fistulas are congenital anomalous communications between the epicardial coronary arteries and either another coronary vessel or a cardiac chamber. The incidence of coronary-to-cardiac chamber drainage (coronary-cameral fistula, CCF) was reported in $0.08-0.3 \%$ of patients who had undergone either elective or emergency diagnostic coronary angiography. ${ }^{1,2}$ Most common anomalous fistulas were described as a drainage from the right coronary artery to the right heart chambers, while only a small percentage are linked to the drainage in the left ventricle. ${ }^{3,4}$ In contrast to large CCF fistulae, which may have a noticeable communication, small fistulas, named "minimae cordis veneae" or the Thebesius venous system, drain into the heart chambers, forming a vascular network in the cardiac lumen. The origin of CCF microfistulas is associated with the fusion failure of the intertrabecular gaps, resulting in the persistence of 
embryonic sinusoids that link the endothelial protrusions and epicardial layer to the coronary arteries. ${ }^{3}$ The clinical consequences may vary from asymptomatic patients to ischemic syndrome-like symptoms, congestive heart failure, arrhythmias, or syncope.5,6 The pathophysiology of these clinical frames could be explained by low resistance through the fistula trajectory, associated with a lower diastolic perfusion pressure within the coronary lumen. However, their impact from a hemodynamic point of view is not significant due to the small amount of blood shunted through the microfistulas, which can vary from $0.12 \%$ to $0.43 \%$ of the total circulating blood flow, as reported by Ravin et al. ${ }^{7}$ Additionally, the presence of several diffuse microfistulas can induce a steal phenomenon, revealed by worsening of the clinical condition, most commonly causing symptoms such as chest pain, shortness of breath, and fatigue. ${ }^{8}$ In case of large fistulas, the current treatment option is represented by surgical embolization. Microfistulas on the other hand have no curative treatment option, neither surgical nor noninvasive. Thus, conservative treatment is the only available choice, which should be initiated based on the clinical status of the patient. ${ }^{9}$ However, vasodilator agents should be avoided, as they can worsen the steal phenomenon.

\section{CASE REPORT}

In this article, we present the case of a 72-year-old female with a significant history of cardiovascular disease and several cardiovascular comorbidities, including chronic congestive heart failure, arterial hypertension, chronic ischemic heart disease, and type 2 diabetes mellitus. Her medical family history for cardiovascular disease was negative. Neither alcohol abuse nor other vicious behavior was admitted. She was hospitalized due to rest dyspnea, dizziness, and fatigue, which had worsened during the week before admission.

A 12-lead ECG was recorded in the emergency room, revealing a trifascicular block (a second-degree atrioventricular block Mobitz II, associated with a right bundle branch block and left anterior fascicular block) and intermittent third-degree block. The ECG also showed negative $\mathrm{T}$ waves in DII, DIII, aVF, V4-V6 leads. The heart rate was 37 beats per minute and the arterial pressure was $126 / 70 \mathrm{mmHg}$. Laboratory analysis showed increased values of serum triglycerides $(201 \mathrm{mg} / \mathrm{dL})$. The value of troponin I was $0.009 \mathrm{ng} / \mathrm{dL}$ upon admission and did not modify throughout hospital admission. The transthoracic echocardiographic examination showed a normal ejection fraction, a slight left ventricular hypertrophy, an enlarged left atrium $(51 \mathrm{~mm})$, and a mitral valve calcification associated with a mild regurgitation, without any signs of ventricular wall motion abnormalities. The E/E' ratio measurement, performed in order to assess the filling pressures, was 5.4 $\mathrm{cm} / \mathrm{s}$, within the normal range (cut-off $<8 \mathrm{~cm} / \mathrm{s}$ ). ${ }^{10}$

The patient complained of chest pain and shortness of breath at admission and showed ischemic modifications on the electrocardiogram, with inversion of $\mathrm{T}$ waves in the inferior and lateral leads. In order to assess a possible myocardial ischemia, a coronary angiography was performed. Upon contrast injection, at a glance, the left coronary tree was free of significant atherosclerotic lesions, and so was the right coronary artery tree, which was dominant. A persistent capillary blush was present at the apex site, within the left ventricular chamber, draining from the distal segments of both the anterior descending artery and the right coronary artery (Figure 1). The aspect of the apical blush was similar to a ventriculography. The intramural vessel network generating a left ventricle angiogram image of this kind was suggestive for persistent Thebesian vessels connecting the two coronary arteries and the one cardiac chamber.

Given that this condition has no curative treatment, a drug therapy based on beta-blockers and angiotensinconverting enzyme inhibitors was initiated. However, the patient's electrocardiogram still showed trifascicular block with intermittent third degree block. Given that her condition has a class IC indication for permanent cardiostimulation according to the guidelines of the European Society of Cardiology for cardiac pacing, ${ }^{11}$ a Medtronik Relia DDD pacemaker was implanted. Her clinical status improved, and her heart rhythm was stable. Afterwards, her clinical status improved, without complaints of ischemia-like symptoms. She was discharged in a stable condition with the therapeutic plan deployed during hospitalization.

The patient gave her informed consent allowing the publication of her data, and the Ethics Committee of the Clinic of Cardiology approved the publication of the case.

\section{DISCUSSION}

Coronary artery fistulas and microfistulas or persistent Thebesian vessels are a rare congenital condition with an incidence up to $0.2 \%$ in adult patients. ${ }^{1}$ The condition was first described in 1708 by the German anatomist Adam Christian Thebesius, in his graduating thesis named "De circulosanguinis in cord". ${ }^{12}$ Being detected in adult patients, they are considered a failure of closure of the embryonic sinusoids, which served as communication between the epicardial vessels and cardiac cavities 

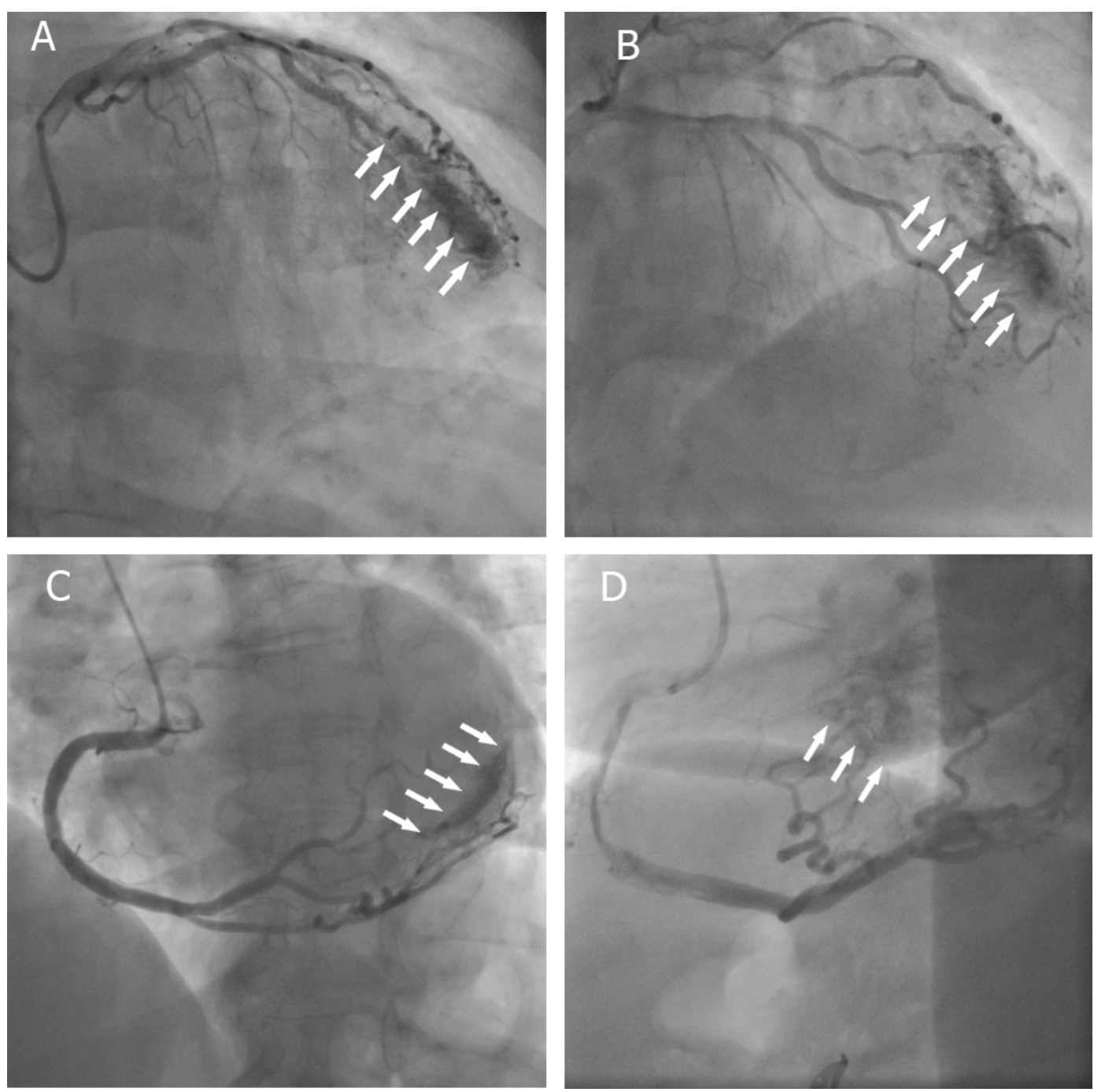

FIGURE 1. Angiographic image: A, B - Left anterior descending artery (LAD) - communication through a network of arterio-sinusoidal microfistulas between the LAD and the left ventricle (white arrows); C, D Right coronary artery (RCA) - communication through a network of arterio-sinusoidal microfistulas between the RCA and left ventricle (white arrows)

with the purpose to provide nutrients to the heart during the intrauterine life. The most common communications are found between an epicardial artery and the right ventricle, as Ansari et al. and Wearn et al. reported. ${ }^{13-15}$ In the case reported in this article, the communication was found between both coronary arteries and the left ventricular chamber, which is a very rare condition. The clinical status of patients diagnosed with this disorder may vary according to the multiplicity of the communications and their size, their length, as well as their origin. Rarely, they produce clinical symptoms such as ischemialike symptoms, syncope, or arrhythmias. Otherwise, they are discovered incidentally while performing an elective coronary angiography. Although microfistulas are considered to cause a blood steal phenomenon in patients with no significant lesions on the coronary arteries, in patients with important atherosclerotic plaques or stenoses, especially in the ostial lesion of the right coronary artery, the fistulas appear to be beneficial by providing blood supply in a retrograde fashion. ${ }^{16}$

\section{CONCLUSION}

The persistence of Thebesian vessels is a rare congenital condition, often discovered incidentally during elective coronary angiography. Usually their hemodynamic significance is limited due to small shunt volume. Therefore, clinical presentation could be poor in symptoms or could lead to an ischemia-like syndrome, syncope, or rhythm disturbances. Hence, diagnosis is made by performing coronary 
angiography, unveiling an extended and diffuse network of small communications between the epicardial arteries and the cardiac chambers, especially to the right ventricle, but in very rare cases, it could link more than one coronary artery with the left ventricle, similar to the case reported in this article. Thebesian vessels are very small, therefore surgical and minimal-invasive methods of treatment are not routinely used. In spite of this major inconvenience, medical treatment based on beta-blockers and angiotensin-converting enzyme inhibitors was reported to be successful as in the case presented in this article.

\section{CONFLICT OF INTEREST}

Nothing to declare.

\section{REFERENCES}

1. Stierle U, Giannitsis E, Sheikhzadeh A, Potratz J. Myocardial ischemia in generalized coronary artery left ventricular microfistulae. Int J Cardiol. 1998:63:47-52

2. Vavuranakis M, Bush CA, Boudoulas $\mathrm{H}$. Coronary artery fistulas in adults: incidence, angiographic characteristics, natural history. Cathet Cardiovasc Diagn. 1995;35:116-120

3. Blake HA, Manion WC, Mattingly TW, Baroldi G. Coronary artery anomalies. Circulation. 1964;30:927s-940s.
4. Ho HH, Cheung $\mathrm{CW}$, Jim MH, Lam L. Coronary cameral fistula. Heart. 2005:91:1540

5. Alkhulaifi AM, Horner SM, Pugsley WB, Swanton RH. Coronary artery fistulas presenting with bacterial endocarditis. Ann Thorac Surg. 1995;60:202-204.

6. Skimming JW, Walls JT. Congenital coronary artery fistula suggesting a "steal phenomenon" in a neonate. Pediatr Cardiol. 1993;14:174-175.

7. Ravin MB, Epstein RM, Malm JR. Contribution of Thebesian veins to the physiologic shunt in anesthetized man. J App/ Physiol. 1965;20:1148-1152.

8. Vogelbach KH, Edmiston WA, Stenson RE. Coronary artery-left ventricular communications: a report of two cases and review of the literature. Cathet Cardiovasc Diagn. 1979;5:159-167.

9. Heper G, Kose S. Increased myocardial ischemia during nitrate therapy: caused by multiple coronary artery-left ventricle fistulae? Tex Heart Inst $\mathrm{J}$ 2005:32:50-52

10. Nagueh SF, Smiseth OA, Appleton CP, et al. Recommendations for the Evaluation of Left Ventricular Diastolic Function by Echocardiography: An Update from the American Society of Echocardiography and the European Association of Cardiovascular Imaging. Eur Heart J Cardiovasc Imaging. 2016;17:1321-1360

11. Brignole M, Auricchio A, Baron-Esquivias G, et al. 2013 ESC Guidelines on cardiac pacing and cardiac resynchronization therapy. European Heart Journal. 2013:34:2281-2329.

12. Thebesius AC. Disputatio medica inauguralis de circulo sanguinis in corde. Leiden; 1708.

13. Wearn JT. The role of the Thebesian vessels in the circulation of the heart. J Exp Med 1928:47:293-315.

14. Wearn JT, Mettier SR, Klumpp TG, Zschiesche LJ. The nature of the vascular communications between the coronary arteries and the chambers of the heart. Am Heart J. 1933;9:143-164.

15. Ansari A. Anatomy and clinical significance of ventricular Thebesian veins. Clin Anat. 2001;14:102-110.

16. Boeder NF, Nef HM, Bauer T. Thebesian veins as drainage to the ventricle: A case report. Cardiovasc Revasc Med. 2017;18:213-214. 